\title{
Reports
}

\section{Properties of the Titanium Prepared by Sodium}

\section{Reduction Process}

\author{
Koemon FUNAKI ${ }^{*}$ and Yuzo SAEKI** \\ * Tokyo Institute of 'Technology \\ 1, Ookayama, Mequro-ku, Tokyo \\ ** National Research Institute for Metals \\ 300, 2-chome Nakameguro, Meguro-ku Tokyo
}

Received Nov. 27, 1964

\begin{abstract}
A series of small-scale sodium process reductions under various conditions were observed. Then, extractions of titanium from the reaction product under various conditions, and the behavior under vacuum of gaseous contaminations during thermal treatment of the titanium obtained by leaching with aqueous solutions were examined. The appreciable reaction between titanium tetrachloride and sodium begins at about $400^{\circ} \mathrm{C}$. At temperatures below $800^{\circ} \mathrm{C}$, however, the titanium and sodium chloride produced do not precipitate but form a solid layer consisting of their mixture which covers the surface of the molten sodium, so that the reaction is brought to an apparent halt before long. When the temperature of the reaction system exceeds $800^{\circ} \mathrm{C}$, the titanium and sodium chloride are allowed to precipitate causing the sodium to come into contact with titanium tetrachloride, and this permits the reaction to proceed continuously. to completion. Hydrogen content is somewhat higher in the titanium obtained by leaching with aqueous solution than in the titanium obtained by vacuum distillation. However, titanium containing a relatively small amount of hydrogen can be obtained when leaching is carried out with water or a diluted hydrochloric acid solution at a temperature as low as possible. The hydrogen contained in the titanium thus obtained can be completely removed by subsequent heating under vacuum at temperatures above $400^{\circ} \mathrm{C}$.
\end{abstract}

\section{Introduction}

In the preceding report ${ }^{11}$, the authors, examining thermoanalytically the reaction between titanium tetrachloride and sodium, arrived at an explanation of the mechanism of this reaction. This led the authors furthers to the establishment of a new method to prepare titanium by using sodium as the reducing agent.

In this paper, a series of small-scale sodium reductions were conducted under 
various conditions, in order to obtain detailed information concerning the mechanism of the reaction between titanium tetrachloride and sodium. Then, extraction of titanium from the reaction product under various conditions, and the behavior under vacuum of gaseous contaminations during thermal treatment of the titanium obtained by leaching with aqueous solutions were examined to obtain titanium with a low gas content.

\section{Observation on the Sodium Reduc- tion of Titanium Tetrachloride}

The apparatus was similar to that shown in the previous paper 1 ). To begin with, an inner vessel which had previously been charged with the purified sodium was inserted into the reaction vessel, while the sodium was kept protected from air by covering it with benzene. Then, the reaction vessel was slowly heated by an electric furnace up to about $200^{\circ} \mathrm{C}$, while a vacuum pump was kept in operation to maintain a sufficiently high vacuum, and then it was filled with argon until a pressure of about $800 \mathrm{mmHg}$ was reached. When a specified temperature was established in the reaction vessel by external heating, the purified titanium tetrachloride was let in drop by drop. As to the amount of titanium tetrachloride, care was taken so that the titanium tetrachloride added might be fully consumed by the reaction. As the heat evolution due to the reaction between titanium tetrachloride and sodium was recognized, the temperature was kept constant by a suitable adjustment of the external heating. After a certain amount of titanium tetrachloride was added, and the heat evolution halted, the addition of titanium tetrachloride was discontinued. After the end of the addition of titanium tetrachloride, the reaction vessel was further kept at the specified temperature for $30 \mathrm{~min}$, and allowed to cool. The inner vessel was then taken out from the reaction vessel, and divided by a vertical cut through the center, so as to exposed a cross section of the contents of the vessel. The cross section was recorded by a photograph.

The conditions under which individual runs of the present experiment were conducted are demonstrated below, together with the cross section of the corresponding contents of the vessel shown in Fig. 1 .

Run No. 1; $70 \mathrm{~g}$ of sodium charged in the inner vessel was kept at $200^{\circ} \mathrm{C}$, and titanium tetrachloride was added to it. In this run, the amount of titanium tetrachloride actually used up by the reaction was too small to be quantitatively detected. After the addition of titanium tetrachloride, the reaction vessel was further kept for $30 \mathrm{~min}$ at the said temperature, and allowed to cool.

Run No. 2; $70 \mathrm{~g}$ of sodium charged in the inner vessel was kept at $400^{\circ} \mathrm{C}$, and titanium tetrachloride was added to it. In this run, titanium tetrachloride equivalent to only about $1 / 20$ of the $70 \mathrm{~g}$ of sodium present actually reacted with the latter. After the completion of reaction, the reaction vessel was further kept for $30 \mathrm{~min}$ at the said temperature, and allowed to cool.

Run No.3; $70 \mathrm{~g}$ of sodium charged in the inner vessel was kept at $600^{\circ} \mathrm{C}$, and titanium tetrachloride was added to it. In this run, titanium tetrachloride equivalent to about $1 / 10$ of the $70 \mathrm{~g}$ of sodium reacted with the latter. After the completion of reaction, the reaction vessel was further kept for $30 \mathrm{~min}$ at the said temperature, and allowed to cool.

Run No.4; 70g of sodium charged in the inner vessel was kept at $700^{\circ} \mathrm{C}$, and titanium tetrachloride was added to it. In this run, titanium tetrachloride equivalent to about $1 / 5$ of the $70 \mathrm{~g}$ of sodium reacted with the latter. After the completion of reaction, the reaction vessel was further kept for $30 \mathrm{~min}$ at the said temperature, and allowed to cool.

Run No.5; 70g of sodium charged in the inner vessel was kept at $830^{\circ} \mathrm{C}$, and tita- 



Fig. 1 Cross sections of the contents of the vessel.

nium tetrachloride was added to it. In this run, titanium tetrachloride equivalent to the full $70 \mathrm{~g}$ of sodium reacted with the latter. After the completion of reaction, the reaction vessel was further kept for $30 \mathrm{~min}$ at $850^{\circ} \mathrm{C}$, and allowed to cool.

Run No.6, $70 \mathrm{~g}$ of sodium charged in the inner vessel was kept at $830^{\circ} \mathrm{C}$, and titanium tetrachloride equivalent to $1 / 2$ of the $70 \mathrm{~g}$ of sodium was added to it. After the addition of titanium tetrachloride, the reaction vessel was further kept for $30 \mathrm{~min}$ at $850^{\circ} \mathrm{C}$, and allowed to cool.

The results of the above-mentioned observations are summarized as follows.

When the reaction temperature is $200^{\circ} \mathrm{C}$ (No.1), the reaction advances only to the extent that the surface of sodium becomes covered by a grayish black thin film. When the reaction temperature is $400^{\circ} \mathrm{C}$ (No.2), the surface of sodium becomes covered by a layer consisting of titanium and sodium chloride which has a thickness of about $2 \mathrm{~mm}$. When the temperature is $600^{\circ} \mathrm{C}$ (No.3), the surface of sodium becomes covered as in the previous case by a layer consisting of titanium and sodium chloride which has a thickness of about $6 \mathrm{~mm}$. When the reaction temperature is $700^{\circ} \mathrm{C}$ (No.4), titanium tetrachloride reacts with sodium much larger than in the cases of 400 and $600^{\circ} \mathrm{C}$.

In turn, when the reaction is carried out at $830^{\circ} \mathrm{C}$ (No.5), a product is attained which is quite different in character from any one of the reaction products described above. It contains no remains of sodium. Not only the upper and lower portions but also the core of the product mass is oc- 
cupied by a mixture of titanium and sodium chloride, which is surrounded by a phase of pure sodium chloride corresponding to nearly $60 \%$ of the total amount present. Observation on the half reduction (No.6) shows that an elliptical mass of sodium, a mixture of titanium and sodium chloride and a phase of pure sodium chloride are located at the reaction surface, in the cen tral and lower parts and in the circumferential part, respectively.

From the above-mentioned experimental results, it may be concluded that: Production of titanium and sodium chloride by the sodium reduction of titanium tetrachloride begins at about $400^{\circ} \mathrm{C}$. However, at temperatures below the melting point of sodium chloride, $800^{\circ} \mathrm{C}$, the titanium and sodium chloride produced do not precipitate but remain forming a solid layer consisting of their mixture which covers the surface of the molten sodium, so that the reaction between titanium tetrachloride and sodium is brought to an apparent halt before long.
When the temperature of the reaction system exceeds $800^{\circ} \mathrm{C}$, the titanium and sodium chloride are allowed to precipitate causing the sodium to come into contact with titanium tetrachloride, and this permits the reaction to proceed continuously to completion.

\section{Extraction of Titanium from the Reaction Product}

As already mentioned, about $60 \%$ of the sodium chloride obtained by the sodium reduction of titanium tetrachloride at $830^{\circ} \mathrm{C}$ occupies a phase consisting almost entirely of the compound. This portion which contains almost only sodium chloride can be mechanically separated from the portion composed of a mixture of titanium and sodium chloride. The latter was now crushed into small granules, and then the titanium was extracted from it by vacuum distillation and by leaching with aqueous solutions under various conditions, as

Table 1 Conditions of Separation of Titanium from the Reduction Product

\begin{tabular}{|c|c|c|c|c|c|c|}
\hline & \multirow{2}{*}{$\begin{array}{c}\text { Sample } \\
\text { weight } \\
\text { (g) }\end{array}$} & \multicolumn{5}{|c|}{ Separation conditions } \\
\hline & & Solution & $\begin{array}{l}\text { Volume } \\
(l)\end{array}$ & $\begin{array}{l}\text { Concentration } \\
\text { (wt } \% \text { ) }\end{array}$ & $\begin{array}{c}\text { Temperature } \\
\left({ }^{\circ} \mathrm{C}\right)\end{array}$ & $\begin{array}{l}\text { Leaching time } \\
\text { (min) }\end{array}$ \\
\hline No. 1 & 5 & $\mathrm{H}_{2} \mathrm{O}$ & 1 & (Final pH 10) & 0 & 30 \\
\hline No. 2 & 10 & $\mathrm{H}_{2} \mathrm{O}$ & 2 & (Final $\mathrm{pH} 10)$ & 20 & 30 \\
\hline No. 3 & 5 & $\mathrm{H}_{2} \mathrm{O}$ & 1 & (Final pH 10) & 40 & 30 \\
\hline No 4 & 5 & $\mathrm{HCl}$ & 1 & 3 & 20 & 30 \\
\hline No. 5 & 5 & $\mathrm{HCl}$ & 1 & 3 & 40 & 30 \\
\hline No. 6 & 5 & $\mathrm{HCl}$ & 1 & 15 & 20 & 30 \\
\hline No. 7 & 5 & $\mathrm{HCl}$ & 1 & 15 & 40 & 30 \\
\hline No. 8 & 5 & \multicolumn{5}{|c|}{ Vacuum distillation at $900^{\circ} \mathrm{C}$ for 2 hrs under $2 \times 10^{-5} \mathrm{mmHg}$} \\
\hline
\end{tabular}


shown in Table 1. Further, all the samples obtained by leaching with aqueous solutions were desiccated for 2 hrs. at $20^{\circ} \mathrm{C}$ under $2 \times 10^{-5} \mathrm{mmHg}$.

Titanium specimens thus obtained were all analyzed for their gas content by means of the N.R.C. vacuum fusion gas analysis apparatus. The results are shown in Table 2.

Table 2 Gas Analyses of Titanium

\begin{tabular}{c|c|c|c}
\hline Sample & $\begin{array}{c}\mathrm{O}_{2} \\
\text { (wt \%) }\end{array}$ & $\begin{array}{c}\mathrm{N}_{2} \\
\text { (wt \%) }\end{array}$ & $\begin{array}{c}\mathrm{H}_{2} \\
\text { (wt \%) }\end{array}$ \\
\hline No.1 & 0.034 & 0.0030 & 0.0271 \\
No.2 & 0.035 & 0.0033 & 0.0282 \\
No.3 & 0.038 & 0.0032 & 0.0355 \\
No.4 & 0.036 & 0.0030 & 0.0341 \\
No.5 & 0.035 & 0.0031 & 0.0389 \\
No.6 & 0.034 & 0.0030 & 0.0520 \\
No.7 & 0.035 & 0.0032 & 0.0578 \\
No.8 & 0.030 & 0.0029 & 0.0021 \\
\hline
\end{tabular}

As seen from the results shown in Table 2, the samples of titanium obtained by leaching with aqueous solutions contain hydrogen in more or less larger amounts than the sample obtained by vacuum distillation. So far as leaching with aqueous solution is concerned, the sample of titanium obtained by extraction with hydrochloric acid is higher in hydrogen content than the titanium obtained by extraction with plain water, and that the higher the concentration of hydrochloric acid used, the more hydrogen contained in sample. Furthermore, there is a tendency that the higher the leaching temperature, the larger the hydrogen content. Regarding the content of oxygen and nitrogen, on the other hand, little difference was found between the samples.

\section{Behavior of Gaseous Contamina- tion During Thermal Treatment of Titanium under Vacuum}

Next, it was inquired how the gaseous contaminations change when the titanium obtained by leaching with aqueous solutions was heated under vacuum. To begin with, $0.5 \mathrm{~g}$ of Sample No. 2 was slowly heated to a prespecified temperature (100, $300,400,600$ and $900^{\circ} \mathrm{C}$ ) and kept for 2 hrs at that specified temperature, while an oil diffusion pump was kept operating. The pressure-time relation found in this experiment is shown in Fig. 2.

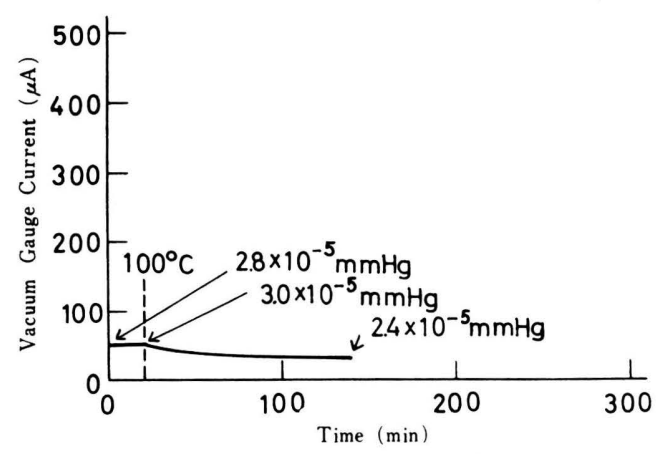

1) Sample was slowly heated to $100^{\circ} \mathrm{C}$, and kept for 2 hrs at $100^{\circ} \mathrm{C}$.



2) Sample was slowly heated to $300^{\circ} \mathrm{C}$, and kept for 2 hrs at $300^{\circ} \mathrm{C}$. 




3) Sample was slowly heated to $400^{\circ} \mathrm{C}$, and kept for 2 hrs at $400^{\circ} \mathrm{C}$.



4) Sample was slowly heated to $600^{\circ} \mathrm{C}$, and kept for $2 \mathrm{hrs}$ at $600^{\circ} \mathrm{C}$.

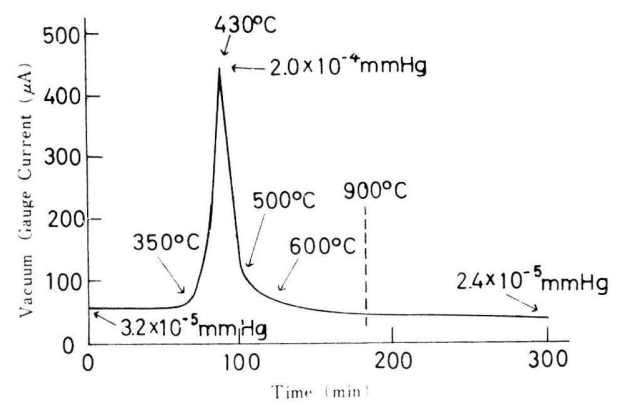

5) Sample was slowly heated to $900^{\circ} \mathrm{C}$, and kept for 2 hrs at $900^{\circ} \mathrm{C}$.

Fig. 2 Pressure-time curves during thermal treatment of titanium under vacuum
As seen from Fig. 2, evolution of gas from titanium becomes vigorous in the neighborhood of $350^{\circ} \mathrm{C}$, and attains a maximum at about $430^{\circ} \mathrm{C}$, almost all the gas being removed at this temperature. Then, each one of these samples treated at a different temperature was analyzed for its gas content. The result is shown in Table 3 .

From this result, it is clear that when heated to temperatures above about $400^{\circ} \mathrm{C}$ the hydrogen contained in titanium obtained by leaching with plain water can be almost completely removed. However, the contents of oxygen and nitrogen do not change during heat treatment under vacuum.

Next, experiments similar to the procedure above-mentioned were performed on Samples Nos. 1, 3, 4, 5, 6 and 7. In all these cases, degassing became vigorous in the neighborhood of $350^{\circ} \mathrm{C}$, came to a maximum at about $430^{\circ} \mathrm{C}$, and almost all the gas was expelled at this temperature. These samples were heated, similarly to sample No. 2 in the preceding experiment, for $2 \mathrm{hrs}$ at 300,400 and $900^{\circ} \mathrm{C}$ under vacuum, and submitted to gas analysis. The results are shown in Table 4 and Fig. 3.

From these results, it is obvious that the hydrogen in the titanium obtained by leaching with aqueous solutions $c$ an be almost completely removed by heating at temperatures above $400^{\circ} \mathrm{C}$ under vacuum, irrespective of the leaching conditions.

As seen rom the above experimental results, little significant difference exists

Table 3 Gas Analyses of Titanium

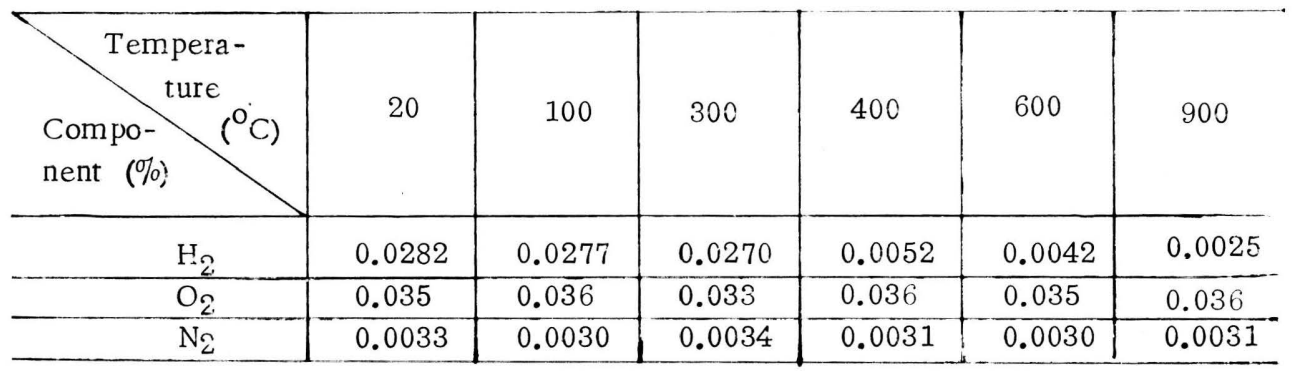


Table 4 Gas Analyses of Titanium

\begin{tabular}{|c|c|c|c|c|c|}
\hline$c_{0}$ & rature & 20 & 300 & 400 & 900 \\
\hline No. 1 & $\begin{array}{l}\mathrm{H}_{2} \\
\mathrm{O}_{2} \\
\mathrm{~N}_{2}^{2}\end{array}$ & $\begin{array}{l}0.0271 \\
0.034 \\
0.0030\end{array}$ & $\begin{array}{l}0.0259 \\
- \\
-\end{array}$ & $\begin{array}{l}0.0048 \\
- \\
-\end{array}$ & $\begin{array}{l}0.0024 \\
0.033 \\
0.0031\end{array}$ \\
\hline No. 3 & $\begin{array}{l}\mathrm{H}_{2} \\
\mathrm{O}_{2} \\
\mathrm{~N}_{2}^{2}\end{array}$ & $\begin{array}{l}0.0355 \\
0.038 \\
0.0032\end{array}$ & $\begin{array}{c}0.0342 \\
- \\
-\end{array}$ & $\begin{array}{l}0.0065 \\
-\end{array}$ & $\begin{array}{l}0.0029 \\
0.037 \\
0.0033\end{array}$ \\
\hline No. 4 & $\begin{array}{l}\mathrm{H}_{2} \\
\mathrm{O}_{2} \\
\mathrm{~N}_{2}\end{array}$ & $\begin{array}{l}0.0341 \\
0.036 \\
0.0030\end{array}$ & $\begin{array}{c}0.0331 \\
- \\
-\end{array}$ & $\begin{array}{l}0.0057 \\
- \\
-\end{array}$ & $\begin{array}{l}0.0028 \\
0.037 \\
0.0032\end{array}$ \\
\hline No. 5 & $\begin{array}{l}\mathrm{H}_{2} \\
\mathrm{O}_{2} \\
\mathrm{~N}_{2}\end{array}$ & $\begin{array}{l}0.0389 \\
0.035 \\
0.0031\end{array}$ & $\begin{array}{c}0.0383 \\
- \\
-\end{array}$ & $\begin{array}{l}0.0085 \\
- \\
-\end{array}$ & $\begin{array}{l}0.0036 \\
0.034 \\
0.0030\end{array}$ \\
\hline No. 6 & $\begin{array}{l}\mathrm{H}_{2} \\
\mathrm{O}_{2} \\
\mathrm{~N}_{2}\end{array}$ & $\begin{array}{l}0.0520 \\
0.034 \\
0.0030\end{array}$ & $\begin{array}{l}0.0510 \\
- \\
-\end{array}$ & $\begin{array}{l}0.0074 \\
- \\
-\end{array}$ & $\begin{array}{l}0.0030 \\
0.036 \\
0.0031\end{array}$ \\
\hline No. 7 & $\begin{array}{l}\mathrm{H}_{2} \\
\mathrm{O}_{2} \\
\mathrm{~N}_{2}^{2}\end{array}$ & $\begin{array}{l}0.0578 \\
0.035 \\
0.0032\end{array}$ & $\begin{array}{c}0.0569 \\
- \\
-\end{array}$ & $\begin{array}{l}0.0092 \\
- \\
-\end{array}$ & $\begin{array}{l}0.0039 \\
0.036 \\
0.0031\end{array}$ \\
\hline
\end{tabular}



Fig. 3 Hydrogen content - temperature curves.

between the titanium obtained by leaching with aqueous solutions and that obtained by vacuum distillation in respect to their oxygen and nitrogen contents, but for a little higher content of hydrogen in the former as compared with the latter, while even from the former titanium containing a relatively low content of hydrogen can be obtained when the leaching is carried out with plain water or a highly diluted hydrochloric acid solution at a temperature as low as possible.

\section{Discussion}

In the preceding report ${ }^{1)}$, the authors, thermoanalytically examining the reaction between titanium tetrachloride and sodium, arrived at the following explanation of the 
mechanism of this reaction: The appreciable reaction begins at about $400^{\circ} \mathrm{C}$. At temperatures below the melting point of sodium chloride, $800^{\circ} \mathrm{C}$, however, the surface of molten sodium becomes covered by a solid phase consisting of the titanium and sodium chloride produced by the first stage reaction and, therefore, the contact between the molten sodium and titanium tetrachloride vapor is prevented. In such circumstances the reaction do not proceed any more practically, since further reaction is only possible by the slow diffusion of titanium tetrachloride vapor through the solid surface layer. When the temperature of the reaction system exceeds $800^{\circ} \mathrm{C}$, molten sodium is again allowed to come into contact with titanium tetrachloride vapor and consequently the reduction reaction proceeds continuously to completion.

The results of the observations on the sodium reduction of titanium tetrachloride reported in this paper have unambiguously verified the above-mentioned inference drawn from the thermoanalytical studies.

Next, the reaction product of the sodium reduction process was compared with that of Kroll process.

In the Kroll process, titanium is obtained as a spongelike mass which is attached to the wall of the reaction vessel ${ }^{2)}$. This fact is not only an obstacle to continuous operation, but causes the deterioration of both yield and purity as well.

In turn, titanium produced in the sodium reduction process does not adhere to the wall of reaction vessel and precipitates readily to the bottom, while the wall of the reaction vessel is kept covered with a phase of pure sodium chloride. This makes a great advantage of the sodium reduction process over the Kroll process as far as the possibility of operating the process in a continuous manner is concerned and also with regard to the yield and purity of the product.

Moreover, in the Kroll process, the reaction between titanium tetrachloride and magnesium is carried out in the presence of $10-20 \%$ (by weight) excess of magnesium ${ }^{3)}$. On the other hand, in the sodium reduction process, titanium tetrachloride and sodium can in principle be used in stoichiometric quantities. This difference may rise from the reduction mechanism.

In the titanium extraction process, the most significant difference between the sodium reduction process and the Kroll process is the fact that, while in the former the aqueous leaching of the reaction product is available for the separation of the titanium, it is not so in the latter. The applicability of aqueous leaching makes an additional contribution to the promise of continuous operation of the sodium reduction process.

Hydrogen content is somewhat higher in the titanium obtained by leaching with aqueous solution than in the titanium obtained by vacuum distillation, but the hydrogen in the former can be almost completely removed by heating under vacuum at temperatures above $400^{\circ} \mathrm{C}$. In actual operation, moreover, such hydrogen residue may not come into question because it is to be removed during the vacuum melting of titanium.

\section{Summary}

The results may be briefly summarized as follows.

1) The appreciable reaction between titanium tetrachloride and sodium begins at about $400^{\circ} \mathrm{C}$. At temperatures below $800^{\circ} \mathrm{C}$, however, the titanium and sodium chloride produced do not precipitate but form a solid layer consisting of their mixture which covers the surface of the molten sodium so that the reaction is brought to an apparent halt before long. When the temperature of the reaction system exceeds $800^{\circ} \mathrm{C}$, the titanium and sodium chloride 
are allowed to precipitate causing the sodium to come into contact with titanium tetrachloride, and this permits the reaction to proceed continuously to completion.

These conclusions drawn from the observation on the reaction have unambiguously verified the inference drawn from the thermoanalytical study.

2) For the extraction of titanium from the reaction product, not only vacuum distiliation but alsc leaching with aqueous solution is applicable. Little significant difference exists between the titanium obtained by leaching with aqueous solution and that obtained by vacuum distillation in respect of their oxygen and nitrogen contents but the content of hydrogen in the former is slightly higher as compared with the latter, while even from the former titanium containing a relatively small amount of hydrogen can be obtained wher leaching is carried out with plain water or a highly diluted hydrochloric acid soiution at a temperature as low as possible.
3) Irrespective of the conditions under which the reaction product is subjected to leaching with aqueous solution, the hydrogen contained in the titanium thereby obtained can be completely removed by subsequent heating under vacuum at temperatures above $400^{\circ} \mathrm{C}$.

The authors thank the Ministry of Education for the financial support granted for this research.

\section{Literature:}

1) K. Funaki, Y. Saeki, Bull. Tokyo Inst. Tech. No. 52, 27(1963); Trans. Metal. Res. Inst. Metals 6, 73(1964).

2) F.S. Wartman, D.H. Baker, J.R. Nettle, V.E. Homme, J., Electrochem. Soc. 101 507(1954).

3) F.S. Wartman, J.P. Walker, H.C. Fuller, M.A. Cook, E.L. Anderson, U.S. Bur. Mines Rept. Invest. .4519(1942); W. J. Kroll, Met. Ind. 87, 105(1955). 